Hydraulic Engineering Repository

Ein Service der Bundesanstalt für Wasserbau

Huang, Wilbur; Millet, Richard; Shewbridge, Scott E.; Perri, Juan; Vargas, Juan;

Inamine, Mike; Mahnke, Steve

\title{
Levee Erosion Screening Process
}

Verfügbar unter / Available at:

https://hdl.handle.net/20.500.11970/100300

Vorgeschlagene Zitierweise / Suggested citation:

Huang, Wilbur; Millet, Richard; Shewbridge, Scott E.; Perri, Juan; Vargas, Juan; Inamine, Mike; Mahnke, Steve (2010): Levee Erosion Screening Process. In: Burns, Susan E.; Bhatia, Shobha K.; Avila, Catherine M. C.; Hunt, Beatrice E. (Hg.): Proceedings 5th International Conference on Scour and Erosion (ICSE-5), November 7-10, 2010, San Francisco, USA. Reston, Va.: American Society of Civil Engineers. S. 305-315. 


\title{
Levee Erosion Screening Process
}

\author{
Wilbur Huang ${ }^{1}$, Richard Millet ${ }^{1}$, Scott Shewbridge ${ }^{1}$, Juan Perri ${ }^{1}$, Juan Vargas $^{1}$ \\ Mike Inamine ${ }^{2}$, and Steve Mahnke
}

${ }^{1}$ URS Corporation, 2870 Gateway Oaks Drive, Suite 150, Sacramento, CA 95833; PH (916) 679-2260; email: wilbur_huang@urscorp.com

${ }^{2}$ Department of Water Resources, P. O. Box 942836, Sacramento, CA 94236

\begin{abstract}
The California Department of Water Resources' Urban Levee Geotechnical Evaluations Program is evaluating urban levees in the Sacramento and San Joaquin river systems. A three-tiered Erosion Screening Process (ESP) has been developed to qualitatively assess the current risk of erosion failure on a levee's waterside slope. Erosion is caused mainly by a weakened geometric levee cross section or poor initial construction coupled with high flow velocity and/or wave action. Levees are evaluated through this three-tiered screening process until the erosion risk potential is determined. Each of the tiers progressively increases in detail. Tier one assesses overall geometry, fetch length, and historical performance. In the second tier, assessments are performed to evaluate the levee's surface resistance to velocity and wave shear stress. Also, field reconnaissance verifies expected levee performance and look for signs of erosion or unstable conditions. In the third tier, the ESP analyzes levee geometry, river geometry, soil and vegetation types, wind-wave impacts and river velocity impacts to categorize levee reaches into a high, medium, or low erosion risk.
\end{abstract}

\section{INTRODUCTION}

\section{Purpose}

The objective of this erosion screening process is to make a qualitative assessment of the potential for erosion failure on a levee's waterside slope. This paper presents the methodology that will be used to assess erosion potential in specific locations of the Sacramento and San Joaquin levee systems, which are being evaluated by the California Department of Water Resources' (DWR) Urban Levee Geotechnical Evaluations (ULE) Program.

\section{Scope and Background}

This qualitative analysis builds upon knowledge gained from both previous and concurrent erosion studies conducted by Ayres Associates, the United States Army Corps of Engineers (USACE), and others. However, it differs from those studies in that it provides additional data and an approach customized to DWR's needs. Light detection and ranging (LiDAR) and bathymetry surveys completed as a part of the ULE Program allow previously unknown erosion sites (like those fully beneath a lowwater surface) to be included in DWR's mitigation prioritization activities. In addition, 
factors like wind and vegetation are reflected in the URS Erosion Screening Process (ESP) spreadsheet for this work.

A levee site with erosion risk is defined as a site where failure is likely to occur without intervention. Erosion risks are increased by a number of factors, which may include:

- Compromised levee prism geometry

- Geomorphologic trends, as indicated by historical damage

- River flow velocity and shear

- Wind-wave shear stress

- Construction from erodible materials

- Presence of detrimental vegetation

- Absence of beneficial vegetation or other slope protection

The erosion potential assessment is conducted using six pieces of information:

- Levee geometry

- Water current characteristics

- Wind characteristics

- Armor characteristics

- Vegetation characteristics

- Soil type

Erosion risks to riverine levees will most likely be due to a weakened levee cross section or poor initial construction coupled with high flow velocity and/or wave action. In large, open bodies of water like a bypass, wind-wave damage is expected to be a dominant cause of erosion. Erosion caused by factors like surface runoff, boat wakes, and embankment overtopping during a flood were not considered for ESP.

The risk potential is quantified by the ratio of the calculated total erosion (TE) and levee width (LW) at the pertinent water surface elevation (WSE) or levee effective width. Levee sites that meet threshold criteria for any risk factors are ranked to establish one of three risk levels:

1. High Erosion Risk. If the calculated TE is greater than the 25 percent of the effective width of the levee, the levee site is at immediate risk of an erosional failure during either a flood or a normal flow condition (TE/LW $>25 \%$ ).

2. Medium Erosion Risk. If the calculated TE is in between 25 percent to 5 percent of the effective width of the levee, the levee site is at risk for failure due to weaknesses, but no immediate threat is apparent $(5 \%<\mathrm{TE} / \mathrm{LW}<25 \%)$.

3. Low Erosion Risk. If the calculated TE is less than the 5 percent of the effective width of the levee, the levee site does not show evidence of erosion potential that is cause for concern. There is either little threat from wind-wave impact and insignificant evidence of geometric deficiency or historical erosion problems, or the levee's surface material adequately resists predicted velocity and wave shear stress during a given flood event (TE/LW $<5 \%$ ).

Current ULE Program ESP will use the program's LiDAR topography and bathymetry survey data to compare actual levee geometry with the USACE standard 
levee prism. Velocity, wind-wave shear stress, and erosion fragility during a given event will be compared to the strength of existing levee materials. Specific criteria and procedures for identifying sites at risk for erosion failure are described in the next section.

\section{EVALUATION METHODOLOGY}

ESP will be performed on program levees in 15 ULE Program study areas.

Figure 1 illustrates the logic and three-tiered process for ESP.

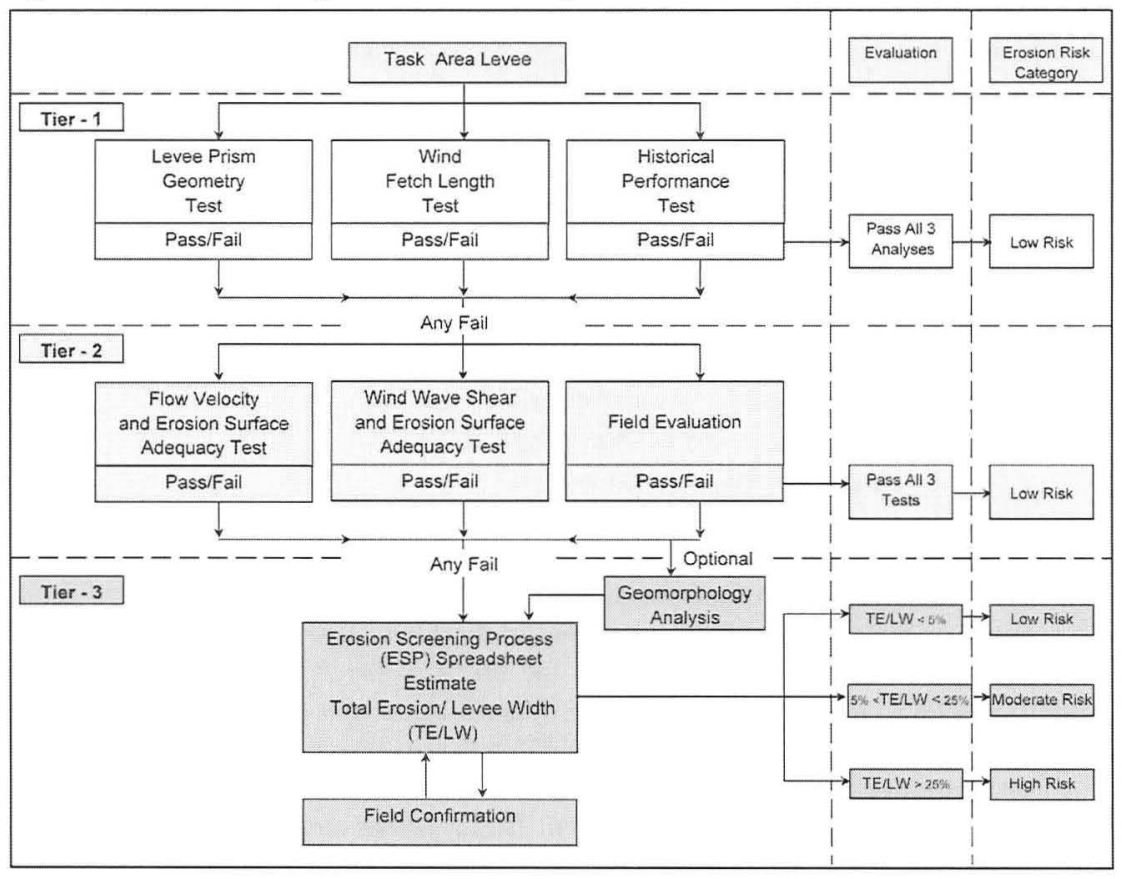

Figure 1. Erosion Screening Process Logic Diagram

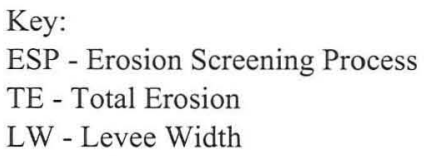

All program levees will be analyzed for the risk factors of tier one: geometry, fetch length, and historical performance. If a levee site passes all three tests in the first tier, it will be labeled as a low erosion risk site. If a levee site fails any of the three tests in the first tier, or if its historical performance is deemed questionable, the site will be advanced to the second tier for further study. 
In the second tier, tests will be performed to evaluate the levee's surface resistance to velocity and wave shear stress. Field reconnaissance will verify expected levee performance and look for any signs of erosion or unstable conditions. If a levee site passes all three tests in the second tier, it will be labeled as a low erosion risk site, due to the fact that the compromised embankment has sufficient protection from velocity and wind shear stress. If a levee site fails any of the three tests in the second tier, it will be advanced to the third tier for further study.

In the third tier, ESP spreadsheet evaluation will be conducted on levee sites failing second tier tests. The ESP spreadsheet analyzes levee geometry, river geometry, soil and vegetation types, wind-wave impacts and velocity impacts to categorize tier three sites into high, medium, or low erosion risk sites.

\section{Levee Prism Geometry Test}

Specifications for a standard levee prism cross section on the Sacramento River Flood Control Project (SRFCP) are set forth in a Memorandum of Understanding (MOU) between USACE and the State of California dated November 30, 1953 (USACE and State of California, 1953). This MOU calls for a standard levee section to be constructed and maintained within the limits of the flood control system.

The MOU provides guidelines and specifications for:

- Infrastructure projects comprising the SRFCP

- Levee construction standards

- Cost of the SRFCP completion

- Responsibilities of the United States and the State of California with regard to completion of construction and operation of the SRFCP

Levee construction standards presented in the MOU also specify how levees will be maintained after construction within the limits of the flood control system. The MOU applies to levees authorized by the Flood Control Act of 1944. Not all existing levees in California have been constructed to this standard. For example, some levees constructed prior to 1944 may not meet the standard levee prism as specified in the MOU. Additionally, San Joaquin River Basin levees are not subject to MOU provisions. However, for consistency, this standard is considered for all tasks under ULE Program ESP.

To highlight deficiencies, ESP compares levees in the Sacramento River and San Joaquin River Basins to one of two standard levee prisms: one for river levees and one for bypass levees. Standard levee prism geometries are defined in Table 1.

\section{Table 1. USACE Standard Levee Prism Geometry}

\begin{tabular}{|l|c|c|c|c|}
\hline Levee Locations & $\begin{array}{c}\text { Crown Width } \\
\text { (feet) }\end{array}$ & $\begin{array}{c}\text { Riverside Slope } \\
\text { (feet/feet) }\end{array}$ & $\begin{array}{c}\text { Landside Slope } \\
\text { (feet/feet) }\end{array}$ & $\begin{array}{c}\text { Freeboard } \\
\text { (feet) }\end{array}$ \\
\hline $\begin{array}{l}\text { River and Tributary } \\
\text { Levees }\end{array}$ & 20 & $3 \mathrm{H}: 1 \mathrm{~V}$ & $2 \mathrm{H}: 1 \mathrm{~V}$ & 3 \\
\hline Bypass Levees & 20 & $4 \mathrm{H}: 1 \mathrm{~V}$ & $3 \mathrm{H}: 1 \mathrm{~V}$ & 6 \\
\hline
\end{tabular}


To compare a standard levee prism to a given levee cross section, this test matches the top of the prism's landside to the levee's landside intersection with a given water surface elevation. This elevation is defined by the 200-year water surface, plus 3 feet. In any situation where the top of the levee is less than the given water surface elevation, an erosion evaluation was not performed. The standard levee prism is 20 feet in width at the crown with a slope of 3 horizontal to I vertical ratio (3H:1V) on the waterside. This comparison is one component of the first tier of the ESP.

Figure 2 illustrates geometric test at a typical levee erosion site. At any area on the waterside where the standard levee prism exceeds the existing levee section, the levee's integrity is considered compromised. Areas with extensive erosion may be subject to significant risk of erosion failure.

If an eroded area does not meet the standard levee prism geometry, but maintains a berm width of 35 feet or more (Ayres, 2007), that section will not be considered critical. Berm width is the horizontal segment of the bank that extends from the levee toe to the top of the riverbank.

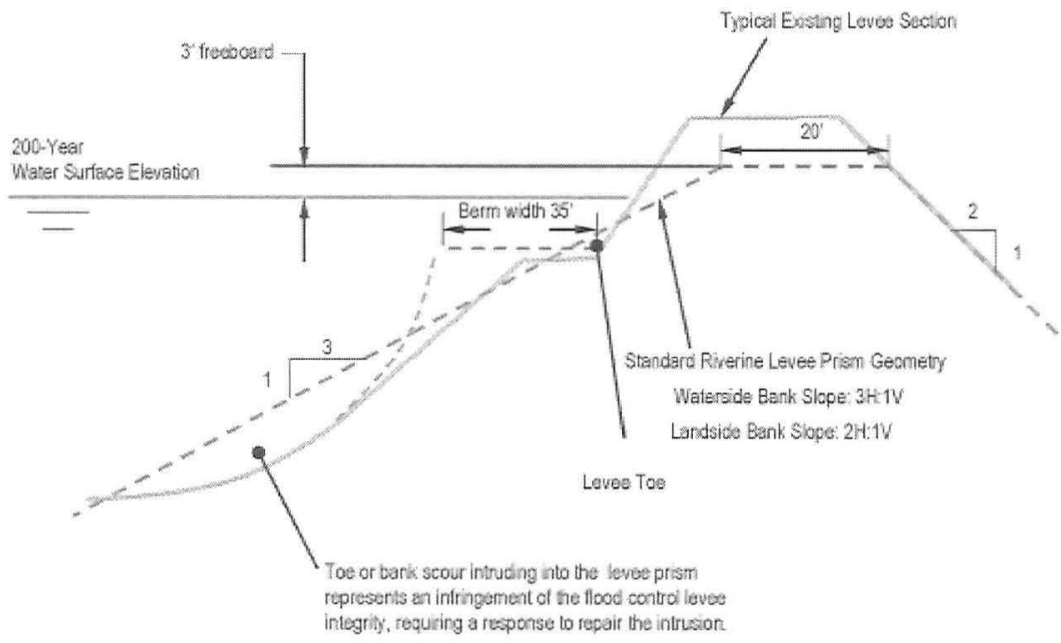

\section{Figure 2. Placement of Standard Levee Prism Geometry within a Riverine Levee Section}

Topographic data including land survey data on the levees and bathymetry data in the channel of perennial rivers are needed to generate existing levee cross sections to compare with the standard levee prism. Since the ULE Program began in 2007, land survey data have been collected using LiDAR survey technology. Bathymetry data collection began in 2008. In areas where recent survey data are not available, the 1997 
USACE Comp Study (USACE, 2002) can provide supplementary data adequate for this analysis. Table 2 lists survey data types and their availability.

Table 2. Availability and Types of Topographic Data

\begin{tabular}{|l|c|c|c|c|c|c|c|}
\hline Data Type & Availability & $\begin{array}{l}\text { Horizontal } \\
\text { Datum }\end{array}$ & $\begin{array}{l}\text { Vertical } \\
\text { Datum }\end{array}$ & $\begin{array}{l}\text { Land } \\
\text { Survey }\end{array}$ & $\begin{array}{l}\text { Bathymetry } \\
\text { Survey }\end{array}$ & Points & Contours \\
\hline $\begin{array}{l}\text { 2007 DWR/URS } \\
\text { LIDAR Data }\end{array}$ & Yes & $\begin{array}{c}\text { UTM } \\
\text { NAD1983 }\end{array}$ & $\begin{array}{c}\text { NAVD } \\
1988\end{array}$ & Yes & - & Yes & - \\
\hline 2008 DWR/URS & Yes & State Plane & NAVD & - & Yes & Yes & - \\
Bathymetry Data & NAD 1983 & 1988 & & Yes & Yes & Yes \\
\hline $\begin{array}{l}\text { 1997 USACE } \\
\text { Comprehensive } \\
\text { Study Survey Data }\end{array}$ & Yes & $\begin{array}{c}\text { State } \\
\text { Plane-NAD } \\
1983\end{array}$ & $\begin{array}{c}\text { NGVD } \\
1929\end{array}$ & Yes & & & \\
\hline
\end{tabular}

\section{Wind Fetch Length Test}

Concurrent with prism geometry test and, as part of the first tier tests, windwave effects, will be considered wherever applicable. Bypasses and large river confluence areas may be subject to wind exposure that allows wave generation and wave erosion. Areas with more than 1,000 feet of open water for wind to act upon are the most likely areas to suffer wind-generated wave erosion. For this test, fetch length is measured as the maximum open water distance at a 45 degree angle to the levee's waterside slope (USACE, 1989).

In some instances, such as where the fetch is measured on a sharp bend, test by these methods may result in a fetch length greater than 1,000 feet, even within a narrow riverine channel where wind is much less likely to have a serious impact. As a result, an additional criteria requires that the local width of the channel be greater than 700 feet for the fetch length test to be performed. Wherever overall channel width is less than 700 feet, or the fetch length is less than 1,000 feet, little risk of wind-wave damage is presumed.

\section{Historical Performance Test}

As a final component of the first-tier test, available historical erosion data will be evaluated for any long-term erosion trends. Data will come from existing information provided by DWR and USACE, or from other consultants like Ayres and William Lettis \& Associates. As the information is available, recent observations and repairs will be plotted for each study area to evaluate geomorphologic trends. Based on historical performance test, sites showing significant changes to their channel or bank will be added to the list of sites for be further evaluation under second tier tests. 


\section{Flow Velocity and Erosion Surface Adequacy Test}

For erosion sites that fail first tier tests, peak flow and local velocity will be obtained from the USACE Comp Study or other available studies. Where existing data are not available, the USACE Alpha method described in USACE Engineering Manual (EM) 1110-2-1601 (USACE, 1991) will be used to estimate local peak velocities in the cross section. These data will be compared to the levee's waterside slope strength, as determined from recent ULE Program geotechnical boring logs and from field verification.

Riverine erosion occurs most commonly when levee material cannot resist the scouring forces of high-velocity flow. EM 1110-2-1601 recommends a set of permissible mean channel velocities for use as a guide to design non-scouring flood control channels. As part of second tier testing, ESP will apply the recommended velocity set listed in Table 3 to potentially problematic levee embankments to determine whether the embankment can withstand scour.

Table 3. Maximum Design Velocities Recommended by the USACE for Flood Control Channels

\begin{tabular}{|c|c|c|}
\hline \multirow[t]{2}{*}{ Levee Material } & \multicolumn{2}{|c|}{$\begin{array}{l}\text { Maximum Design Velocity } \\
\text { (feet per second) }\end{array}$} \\
\hline & $\begin{array}{l}\text { Mean Channel Velocity } \\
\text { at Straight Channel }\end{array}$ & $\begin{array}{c}\text { Depth-Averaged Velocity } \\
\text { at Channel Bend }\end{array}$ \\
\hline Fine Sand, Sandy Silt & \multicolumn{2}{|c|}{2.0} \\
\hline Silt Clay, Soft Shale & \multicolumn{2}{|c|}{3.5} \\
\hline Coarse Sand, Fine Gravel, Clay & \multicolumn{2}{|c|}{6.0} \\
\hline Vegetation-lined Earth & \multicolumn{2}{|c|}{8.0} \\
\hline $\begin{array}{l}\text { Poor Rock (Soft Sandstone, Non- } \\
\text { uniform Revetment) }\end{array}$ & \multicolumn{2}{|c|}{10.0} \\
\hline $\begin{array}{l}\text { Good Rock (Riprap, Uniform } \\
\text { Revetment) }\end{array}$ & \multicolumn{2}{|c|}{15.0} \\
\hline
\end{tabular}

To account for the velocity increase on the outside of channel bends, EM 1110-2-1601 recommends an adjustment to the mean channel velocity. This adjustment factor reflects the depth-averaged velocity at a point 20 percent of the slope length from the toe of slope, where velocities are presumed highest for the embankment. The recommended USACE velocity adjustments in EM 1110-2-1601 on page 3-5 and in Plate B-33 are shown below (see Figure 3). The adjustment factor ranges from 1.0 to 1.6 and depends on the bend's centerline radius divided by the

\footnotetext{
${ }^{1}$ Reference from EM 1110-2-1601, Page 2-16: EM 1110-2-1601 suggests 20 fps for Good Rock. The velocity number has been adjusted for ESP based on prior DWR levee repair project experience in the Sacramento and San Joaquin River Basins.
} 
channel's surface width, as well as the bend's angle and aspect ratio (bottom width/depth). This recommended adjustment does not apply to the side slopes of straight channels.

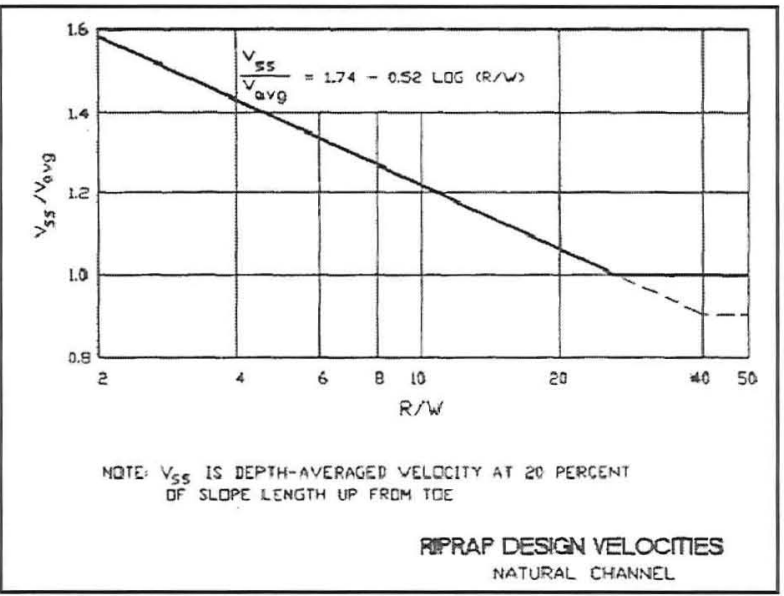

Figure 3. Plate 33, USACE Engineering Manual 1110-2-1601.

\author{
Key: \\ $\mathrm{R}$ - Center-line radius of the bend \\ W - Water Surface width
}

A two-dimensional hydraulic model will predicts the local velocities in a river more accurately, but this information is not available for ULE Program study areas. Because of this lack of information, the following simplified velocity adjustments will be applied for the ESP.

- For inside river bends, velocity will be reduced by up to 20 percent of the channel mean velocity.

- For outside river bends, velocity will be increased by up to 20 percent of the channel mean velocity.

- For levee reaches with a large overbank area, levee toe velocity will be reduced up to 50 percent of the channel mean velocity or $2 \mathrm{fps}$, whichever is higher.

\title{
Wind Wave Shear and Erosion Surface Adequacy Test
}

For areas that fail the first-tier test, the computed wave action shear stress will be compared with levee material strength to determine whether the waterside slope is likely to erode.

The statistical probability of a 200-year flood event occurring simultaneously with a maximum wind event is low. For that reason, the wind speed of a 50 -year wind 
event will be used to compute wave height and stress on the levee during a 100-year flood WSE.

Wind-generated wave shear stress will be computed using USACE guidance, such as the Shore Protection Manual and the Coastal Engineering Manual (USACE, 1984, 2002).

Critical shear stress is the bed shear stress (i.e., tractive force caused by the flow of water over the riverbed) at which the grains or aggregates (i.e., bed material) start to move. Table 4 summarizes the critical shear stress for five types of levee material. These critical shear stress values were derived from URS' ESP User Manual which is, in turn, based on experimental field testing reported by Briaud et al. (2001; 2003) and Hanson and Simon (2001).

\section{Table 4. Critical Shear Stress}

\begin{tabular}{|l|c|}
\hline Levee Material & $\begin{array}{c}\text { Critical Shear Stress } \\
\text { (psf, or pounds per square foot) }\end{array}$ \\
\hline Silt (ML) & 0.003 \\
\hline Sand (SP, SM and mixtures) & 0.014 \\
\hline Clay (CL, CH, SC, GC) & 0.094 \\
\hline Gravel (GP-GW) & 1.058 \\
\hline Boulder and Cobbles & 4.869 \\
\hline
\end{tabular}

\section{Field Evaluation}

For levee sites under consideration in the second tier of ESP, field evaluation will be conducted to verify the levee's current condition and examine the levee for any sign of active erosion. If a geometry evaluation or field evaluation reveal signs of erosion, select field parameters will be collected to perform velocity, wind-wave, and ESP spreadsheet calculations. These parameters will include the levee's geometry, presence or absence of slope protection and vegetation, and slope soil type.

Levee material at each potential erosion site will be compared to the maximum estimated velocity and to wind wave shear stress. Levee material used for comparison will be determined from this field evaluation and recent ULE Program geotechnical boring logs.

\section{ESP Spreadsheet}

If a levee erosion site fails any of the second tier tests, the site will be further analyzed by reviewing existing geomorphology studies, if available, and then by applying URS' ESP spreadsheet (URS, 2009). The ESP spreadsheet was customized for this program from an earlier URS Erosion Toolbox, developed for the USACE as part of the Nationwide Levee Risk Assessment Methodology project (URS, 2007).

The ESP spreadsheet is a risk analysis tool for screening-level assessments of levee erosion failure risk. Based on the input parameters of levee geometry, material 
type, wind-wave and flow velocities, the ESP spreadsheet determines whether a levee can withstand combined erosive forces. Field confirmation will be performed for sites where the ESP spreadsheet indicates a borderline medium or high erosion risk, to confirm the final classification for these sites are correct.

To validate the categorizations provided by the ESP spreadsheet, 50 soil samples were collected throughout the ULE Program study areas; gradation and Atterberg limit tests were performed on the samples. Twelve soil samples were selected for its geographic locations and erosion rate tests were performed for these twelve soil samples using an Erosion Function Apparatus (EFA). These EFA results, along with the conclusions of an independent erosion advisory panel (IEAP, 2009), confirm the applicability of using the ESP spreadsheet and this ESP methodology in ULE Program study areas.

\section{ESP RESULTS}

The ESP spreadsheet calculates the total expected erosion of a site, which is the sum of erosion due to wave bottom currents and wave breaking, and the erosion due to current velocity. As discussed earlier, levee sites are ranked using the threetiered process into one of three levels of erosion risk by comparing total expected erosion with the width of the levee at the pertinent water surface elevations, or a levee effective width. The final risk categories are determined as follows:

- High Erosion Risk. TE/LW > 25\%

- Medium Erosion Risk. . 5\% $<$ TE/LW $<25 \%$

- Low Erosion Risk. TE/LW $<5 \%$

Detailed ESP and ranking results will be documented and included as a part of each study area's Geotechnical Evaluation Report (GER).

\section{REFERENCES}

Ayres Associates, (2007). 2006 Field Reconnaissance Report of Bank Erosion Sites and Site Priority Ranking - Sacramento River Flood Control Levees, Tributaries and Distributaries, Sacramento River Bank Protection Project, USACE. June.

Briaud, J., Chen, H., Li, Y. Li et al. (2003). Complex Pier Scour and Contraction Scour.

Briaud, J., Ting, F., Chen, C. et al. 2001. "Erosion Function Apparatus for Scour Rate Predictions," Journal of Geotechnical and Geoenvironmental Engineering. ASCE, Vol. 127, N. 2, pp. 105-113.

Hanson, G., Simon, A. (2001). "Erodibility of Cohesive Streambeds in the Loess Area of the Midwestern USA," Hydrological Processes. Vol. 15 No 1. pp. 23-38.

IEAP, 2009, An Independent Erosion Advisory Panel was formed in 2009 to provide independent review for the ESP. The IEAP included Jean-Louis Briaud, Tom Smith and Ronald Copeland.

URS. (2007). User's Manual, Erosion Toolbox: Levee Risk Assessment Methodology, USACE Nation Wide Levee Assessment. December.

URS. (2009). User's Manual, Erosion Screening Process Spreadsheet, Urban Levee Geotechnical Evaluation Program. April. 
USACE and State of California. 1953. Memorandum of Understanding (MOU), Respecting the Sacramento River Flood Control Project, November 6.

USACE. (1984). Shore Protection Manual (SPM).

USACE. (1989). EM 1110-2-1414, Water Levels and Wave Heights for Coastal Engineering Design.

USACE. (1991). Engineering Manual (EM) 1110-2-1601, Hydraulic Design of Flood Control Channels. July 1, 1991 Version with revisions dated June 30, 1994.

USACE. (2002). EM 1110-2-1100, Coastal Engineering Manual (CEM), Part II. April 30.

USACE. (2002). Sacramento and San Joaquin River Basins, California, Comprehensive Study, Interim Report. December. 